\title{
REVIEW
}

\section{New insights in the battle between wheat and Puccinia striformis}

\author{
Chunlei TANG, Xiaojie WANG, Yulin CHENG, Minjie LIU, Mengxin ZHAO, Jinping WEI, \\ Zhensheng KANG (凶) \\ State Key Laboratory of Crop Stress Biology for Arid Areas and College of Plant Protection, Northwest A\&F University, \\ Yangling 712100, China
}

\begin{abstract}
Wheat stripe rust caused by Puccinia striiformis f. sp. tritici (Pst) poses a great threat to wheat production worldwide. The rapid change in virulence of Pst leads to a loss of resistance in currently resistant wheat cultivars, which results in frequent disease epidemics. Therefore, a major focus is currently placed on investigating the molecular mechanisms underlying this rapid variation of pathogenicity and coevolving wheat resistance. Limited by the lack of a system for stable transformation of Pst and the difficulties in wheat transformation, it is not easy to generate deeper insights into the wheat- $P s t$ interaction using established genetic methods. Nevertheless, considerable effort has been made to unravel the wheat-Pst interaction and significant progress is being made. Histology and cytology have revealed basic details of infection strategies and defense responses during wheat- $P s t$ interactions, identified cellular components involved in wheat-Pst interactions, and have helped to elucidate their role in the infection process or in plant defense responses. Transcriptome and genome sequencing has revealed the molecular features and dynamics of the wheat-Pst pathosystem. Extensive molecular analyses have led to the identification of major components in the wheat resistance response and in Pst virulence. Studies of wheat-Pst interactions have now entered a new phase in which cellular and molecular approaches are being used. This review focuses on the cellular biology of wheat-Pst interactions and integrates the emerging data from molecular analyses with the histocytological observations.
\end{abstract}

Keywords wheat, strip rust, Puccinia striiformis f. sp. tritici, host defense, pathogen virulence, biotrophic fungus

Received July 20, 2015; accepted August 10, 2015

Correspondence: kangzs@nwsuaf.edu.cn

\section{Introduction}

Wheat (Triticum aestivum) is one of the three most important food crops, along with rice and potato. A large number of pathogenic microorganisms cause severe diseases in wheat, leading to significant yield losses and posing a great threat to the security of wheat production worldwide. Wheat stripe rust, caused by Puccinia striiformis f. sp. tritici (Pst), is one of the most devastating diseases, with the potential to regularly inflict regional yield losses ranging from $0.1 \%$ to $5 \%$, with rare events reaching 5\%-25\%, or even total loss ${ }^{[1]}$. Planting resistant cultivars is the most effective way to control this disease. However, the quick emergence of new virulent races of Pst has led to frequent resistance losses in currently resistant cultivars, which ultimately results in epidemics of wheat stripe rust. The pandemics reported in the 1970s were assumed to be associated with the failure of $Y r 2$ that is known to be present in the cultivars most affected in North Africa, the Indian Subcontinent, the Middle East, East African highlands, and China ${ }^{[2]}$. In the 1990 s, mutation to virulence for $Y r 9$ precipitated an historical epidemic ${ }^{[3]}$. In China, during 1950-2010, virulence mutation of Pst led to seven large-scale cultivar replacements. Stripe rust epidemics have typically been the outcome of interactions between coevolved host materials and pathogens. The evolutionary antagonism between wheat and Pst typically coincides with the gene-for-gene model, based on coevolved resistance $(R)$ genes in wheat and avirulence (Avr) genes in Pst.

During the battle against pathogenic Pst, wheat has evolved a two-layered innate immune system that includes pathogen-associated molecular pattern (PAMP)-triggered immunity (PTI) and effector-triggered immunity (ETI ${ }^{[4]}$. PTI, the first line of defense, is governed by pattern recognition receptors (PRRs) in plant cell membranes that recognize the highly conserved PAMPs of pathogens to

(C) The Author(s) 2015. This article is published with open access at http://engineering.cae.cn 
trigger a relatively weak immune response. ETI, the second line of defense is initiated by archetypical $R$ proteins that directly or indirectly recognize highly variable pathogen molecules called Avr effectors. Compared to PTI, ETI is a rapid and robust response, usually associated with a hypersensitive reaction (HR).

Owing to its scientific and economic importance, the antagonistic wheat-Pst pathosystem has been a focus of research over the past five decades. In the early stages, histological and cytological studies have driven our understanding of the infection process and host responses. Subsequently, the availability of transcriptome and genome sequences for wheat and Pst has promoted the understanding of the molecular events occurring in wheatPst interactions. In this review, we demonstrate the achievements made in the histological and cytological study of wheat- $P s t$ interactions, and discuss new insights into wheat immunity and $P$ st pathogenesis provided by the sequence resources and advanced genomic technologies.

\section{Histochemical and cytological study of wheat-Pst interactions}

\subsection{Infection process of Pst}

Pst is a heteroecious, macrocyclic rust pathogen having a complex life cycle involving five different spore forms. The major phase of the Pst life cycle is the asexual uredinial stage in wheat. Successful Pst infection appears as a mass of urediniospores that erupt from pustules arranged in long, narrow stripes mainly on leaves, as well as on leaf sheaths, glumes and awns of susceptible wheat plants. Barberry species were found to serve as alternate host of $P s t^{[5,6]}$, which solved the century-old mystery of Pst life history. Wheat serves as the primary host of Pst and Berberis spp. as alternate hosts, where sexual reproduction is completed ${ }^{[5,6]}$.

As an obligate biotroph, Pst depends on living wheat cells for growth and reproduction. The infection process for Pst urediniospores in wheat plants can be divided into three major stages, penetration, parasitic/biotrophic growth and sporulation. Histological observations revealed that pathogen penetration occurs mostly within the $12 \mathrm{~h}$ following inoculation, during which time the urediniospores germinate, the germ tubes penetrate through stomata and then subsequently form substomatal vesicles within the stomatal cavity. Following this, intercellular invasive hyphae and haustorial mother cells are formed. Studies using electron microscopy showed that penetration pegs are formed from these cells, followed by an extension of the haustorial neck and then further expansion and maturation of the haustorial body ${ }^{[7]}$. Upon establishment of the haustorium, an infection structure unique to biotrophic pathogens, that makes intimate contact with the host cell membrane and allows for nutrient uptake ${ }^{[8]}$,
Pst enters the most important parasitic/biotrophic stage. Unlike the infection processes in other rust fungi, Pst does not form an obvious appressorium over the stomata ${ }^{[9]}$.

\subsection{Plant response to Pst}

Wheat resistance to Pst can be broadly categorized as allstage resistance (also called seedling plant resistance, SPR) and adult plant resistance (APR) ${ }^{[1]}$. SPR can be detected at the seedling stage and is expressed during all stages of plant growth. However, APR is only expressed during the later stages. Wheat seedling resistance against Pst can be very effective, but it is usually race-specific and can be easily overcome by the rapid evolution of new pathogen races. Histological and cytological studies show that a series of defense responses are involved in wheat seeding resistance against Pst infection. These defenses include cell wall apposition, papilla formation and accumulation of several antifungal compounds, such as lignin, callose, plant hydrolases, reactive oxidative species (ROS), and a $\mathrm{HR}^{[10]}$. Wheat APR against Pst infection shows similar responses to seeding resistance against $P$ st infection, and is initiated as early as the tillering stage, increasing gradually as plants grow, and is most effective at the boot stage ${ }^{[11]}$.

\subsection{Non-host resistance to Pst}

Non-host resistance (NHR), defined as resistance shown by all genotypes of a plant species against all genotypes of a given pathogen species, represents the most robust and durable form of plant resistance in nature. NHR is divided into two types, type I NHR and type II NHR. Type I NHR does not produce visible symptoms whereas type II NHR results in a rapid HR with cell death ${ }^{[12]}$. There are several studies about NHR in rice, Arabidopsis, or broad bean involving attempted Pst infection ${ }^{[13-15]}$. The results show that a continuum of layered defenses is involved in NHR against Pst, including basic incompatibility (Pst germ tubes fail to recognize the stomata of non-host plants), structural and chemical strengthening of the cell wall and induction of several defense-related genes. The leaves of non-host broad bean and rice showed no visible symptoms, indicating type I NHR, but HR with cell death in infection units was also occasionally observed at histological and cytological levels ${ }^{[13,15]}$. Thus HR that cannot be detected as visual symptoms may be observed at the single cell level in type I NHR, which is probably related to low infection probability and an extremely rapid HR in non-host plants. Meanwhile, it is worth noting that all NHR in rice, Arabidopsis and broad bean against $P$ st strongly induce the expression of the salicylic acid (SA) pathway ${ }^{[13-15]}$. Compared with wild type plants, increased fungal growth was observed in an nprl-1 mutant and in NahG transformed plants, which are both insensitive to $\mathrm{SA}^{[14]}$. These results highlight the significance of participation of SA in NHR to Pst. 


\section{A complex and delicate regulatory network in wheat response to Pst}

Histological and cytological studies on the wheat-Pst pathosystem have revealed the features of host resistance to Pst, including necrotic reactions of host cells during haustoria formation, pronounced cell wall apposition in host cells in contact with intercellularly growing hyphae and papillae formation adjacent to the penetration sites of haustorial mother cells ${ }^{[10,16]}$ as well as significant synthesis and accumulation of lignin and callose ${ }^{[10]}$, plant hydrolases $^{[17]}$, and $\operatorname{ROS}^{[18]}$. Moreover, an oxidative burst was observed to be one of the earliest responses of wheat when exposed to an avirulent Pst race ${ }^{[18]}$. Given the broad variety of resistance responses of wheat to Pst, it is important to determine the molecular mechanisms responsible for host resistance.

Plant disease resistance and susceptibility are governed by the combined genotypes of host and pathogen, and depend on a complex interaction and exchange of signals and responses occurring under given environmental conditions. During the long processes of host-pathogen co-evolution, plants have developed various elaborate mechanisms to prevent pathogen infection.

\subsection{Transcriptome analysis revealed the molecular events involved in wheat response to Pst}

Difficulties of wheat transformation and the lack of a transformation system for Pst limited the effectiveness of established genetic and molecular techniques in studying the underlying mechanism of wheat- $P s t$ interactions. In the absence of genome sequences for wheat and Pst, transcriptomics was a powerful approach to interpret the molecular basis of the stripe rust fungus-wheat interaction and major efforts and progress have been made in understanding the transcription profile of host genes involved in response to Pst.

Through construction of a cDNA library from wheat leaves inoculated with a virulent Pst isolates, 5793 ESTs were obtained which gave a set of 2743 unique sequences ${ }^{[19]}$. Annotation analyzes revealed that among the differentially expressed genes, ESTs with putative functions as enzymes of energy and metabolism accounted for the largest category. The second was a category of enzymes with unknown and hypothetical proteins, and the third category was defense proteins ${ }^{[19]}$. Using the cDNAAFLP technique, the dynamic behavior of gene expression profiles was investigated over a time course. Huge amounts of transcript derived fragments (TDFs) of wheat were obtained during the response to the wheat stripe rust fungus, and approximately $4 \%$ of the total TDFs displayed altered expression patterns after inoculation with avirulent or virulent $P s t^{[20,21]}$. Importantly, more than $80 \%$ of the differentially expressed genes were enriched in the early and late infection stages of Pst, with a quench in the middle stage of infection. A series of genes encoding signal molecules expressed soon after pathogen infection were identified as early pathogen-responsive and potentially defense-related genes. A large proportion of the genes in the early infection stage were involved in metabolism, energy, disease defense and signal transduction and were found in both compatible and incompatible interactions ${ }^{[20,21]}$. Plant responses in compatible and incompatible interactions are qualitatively similar, but despite this, the reponses of wheat to virulent or avirulent Pst races were quantitatively different. Comparative analysis of 255 TDFs induced during the incompatible interaction with those in the compatible interaction showed that $161 \mathrm{TDFs}$ $(63 \%)$ were also induced during the compatible interaction, and thus were classified as basal defense-related, while 94 TDFs were expressed preferentially in the incompatible interaction.

Like the SPR, APR is also clearly associated with extensive hypersensitive cell death of host cells and localized production of $\operatorname{ROS}^{[11]}$. In the APR to the stripe rust fungus by Kariega $\times$ Avocet $\mathrm{S}$ wheat derived lines, histopathological and RT-PCR analyzes detected slightly stronger induction of pathogenesis-related (PR) proteins, including PR1, PR2 and PR5. Also they revealed that lignification and production of chitinases may contribute to $\mathrm{APR}^{[22]}$. Moreover, using cDNA-AFLP and quantitative RT-PCR, Mallard et al. ${ }^{[22]}$ found that in the wheat $\mathrm{cv}$. Camp Remy APR expression of some resistance/defenserelated genes was modified during transition from seedling to adult plant growth. Meanwhile, Coram et al. ${ }^{[23]}$ using the wheat Affymetrix Gene Chip, identified 99 induced transcripts specific to $\operatorname{Yr} 39$ high temperature adult plant resistance with two $\mathrm{F}_{7}$ recombinant inbred lines derived from an Avocet $\mathrm{S} \times$ Alpowa cross that differed at the $\operatorname{Yr} 39$ locus. Through a suppressive subtractive hybridization, large numbers of genes involved in defense responses and signal transduction were identified in association with the APR in wheat cv, Xingzi 9104. High transcript levels from some PR protein genes were maintained for longer in adult plants than in seedlings after $P s t$ infection. For the first time, concanavalin A-like lectin/glucanase was found to be involved in plant defense against pathogen infection ${ }^{[24]}$.

Transcriptomics studies of wheat- $P s t$ interactions have thus provided us with a broad overview of the molecular events during wheat resistance or susceptible response to Pst. Moreover, abundant sequence data has been obtained, which has accelerated the application of reverse genetics to the study of wheat resistance mechanisms.

\subsection{Metabolism}

Among the transcriptome dynamics of wheat responses to Pst, genes involved in metabolism and energy are strongly represented, indicating the importance of regulation of 
metabolism in wheat responses to the attack of both avirulent and virulent Pst. To clarify the roles of metabolism in wheat- $P s t$ interactions, induced genes participating in different metabolic pathways have been selected for further research. Xu et al. ${ }^{[25]}$ found that the acireductone-dioxygenase, participating in the methionine salvage pathway, was induced during compatible wheatPst interaction, abiotic stresses and exogenous ethylene treatment, thus implying that this enzyme may take part in the ethylene synthesis pathway and respond to signals resulting from biotic and abiotic stresses. The ceramidase gene Ta-CDase, which was induced during the wheat resistance response to avirulent $P$ st isolate, may play a role in regulating the conversion of sphingolipid compounds involved in defense reactions ${ }^{[26]}$. TaAlaAT1 encoding an aminotransferase may function as a regulator of plant carbon and nitrogen metabolism ${ }^{[27]}$.

Hampered by the difficulty of the wheat transformation system, the functions of wheat genes were initially proposed based on their expression patterns. Application of barley stripe mosaic virus-induced gene silencing (VIGS) in evaluating the role of Lr21 during wheatPuccinia triticinia interaction provided a new approach for characterizing the function of wheat genes ${ }^{[28]}$. VIGS has been successfully used to study wheat- $P s t$ interaction and has provided much evidence for the function of metabolism-related genes in wheat resistance. Glycerol-3-phosphate (G3P) is a proposed regulator of plant defense signaling in basal resistance and systemic acquired resistance $(\mathrm{SAR})^{[29]}$. Increased G3P accumulation accompanied by induced SAR was observed in the incompatible wheat-Pst interaction indicating that G3P-mediated SAR was present in graminaceous plants ${ }^{[30]}$. The GLY1encoded glycerol-3-phosphate dehydrogenase and GLI1encoded glycerol kinase are two key enzymes engaged in two parallel pathways for G3P metabolism. Silencing them compromised wheat resistance to $P$ st, with suppressed SA accumulation and $P R 1$ expression ${ }^{[30]}$, suggesting that disruption of G3P synthesis affected the host resistance to the pathogen.

During chlorophyll catabolism, chlorophyll is degraded to safe linear tetrapyrroles through a series of reactions catalyzed by chlorophyllase, magnesium dechelatase, and pheophorbide A oxygenase (PaO). Disruption of expression of the $\mathrm{PaO}$ homolog TaLls 1 resulted in the accumulation of pheophorbide $\mathrm{A}$, which induces further cell death and enhanced wheat tolerance to $P s t$, by stimulating $\mathrm{H}_{2} \mathrm{O}_{2}$ production $^{[31]}$. Red chlorophyll catabolite accumulation in leaf tissues transiently overexpressing TaLls 1 also led to $\mathrm{H}_{2} \mathrm{O}_{2}$ production and cell death. The data suggested a close relationship between chlorophyll catabolites and $\mathrm{H}_{2} \mathrm{O}_{2}$ accumulation, and resistance to Pst in wheat.

Due to the ability to maintain high levels of ascorbate in different cell compartments, the ascorbate-glutathione cycle is important in protecting the organism against reactive oxygen species in many organisms. Feng et al. ${ }^{[32]}$ found that the homolog of monodehydroascorbate reductase (MDHAR) in wheat, TaMDHAR, which is one key enzyme in the ascorbate-glutathione cycle maintaining the reduced sate of ascorbate, was involved in the early stage of wheat-Pst interaction, which is the key stage for the ROS burst. Silencing of TaMDHAR in wheat cv. Xingzi 9104 resulted in enhanced wheat resistance to Pst by inhibiting sporulation, suppressing Pst hypha growth and increasing necrotic areas in the adult stages. It was deduced that TaMDHAR could contribute to the APR of Xingzi 9104 through ROS metabolism as regulated by the ascorbate-glutathione cycle ${ }^{[32]}$.

These limited examples only reveal a small part of the metabolic regulation in wheat defense responses. Nevertheless, it seems enough for us to get a glimpse of the potential importance of basal metabolism in maintaining cell homeostasis and the complicated regulatory roles in wheat resistance to Pst.

\subsection{Defense proteins}

Pathogen attack activates all the vital activities responsible for resistance or susceptibility responses to the pathogens. Therefore, the defense responses to plant infection by pathogens have received much attention. Transcriptome analyses revealed various processes including appearance of multiple proteins involved in the defense response to the wheat stripe rust fungus. Defense-related proteins identified can be divided mainly into the following major categories: PR proteins, stress-related proteins, cell death-related proteins, Rproteins, auxin-related proteins, proteins involved in the phenylpropanoid pathway and so on $^{[19-21,24]}$.

\subsubsection{Pathogenesis-related proteins}

Expression profiling analyses have shown that some PR genes maintain high expression levels in wheat after Pst infection, and persist for longer in the adult plants than in seedlings after Pst infection, indicating the involvement of PR proteins in wheat SPR and APR. Thaumatin like protein $^{[33]}$ and $\beta-1,3$-glucanase ${ }^{[34]}$ were upregulated in both compatible and incompatible wheat-Pst interactions, during which they may participate in the basal defense of wheat against Pst. The higher level of transcription and greater abundance of protein labeling in the incompatible wheat- $P s t$ interaction than in the compatible interaction further suggested their positive role in wheat resistance to $P s t^{[33,34]}$. Combined with the induced expression in response to phytohormones (SA, jasmonic acid and abscisic acid), it is reasonable to suggest that these two PR proteins are involved in both SAR and induced systemic resistance. Another PR protein, TaPR10 was 
shown to participate in the defense responses of APR to Pst, due to a much higher expression level in the resistant adult stage than in the susceptible seedling stage ${ }^{[35]}$. Although the defense role of PR proteins in plants against rust fungi is far from being fully understood, recent results indicate their involvement in resistance response of wheat to the stripe rust fungus. Due to the constitutive role of PR proteins in wheat defense to Pst, some have been taken as the marker proteins to evaluate wheat resistance response to Pst in the following studies.

\subsubsection{Cell death related genes}

The HR is a robust defense response frequently associated with $R$ gene mediated resistance, and includes the death of plant cells local to the site of infection. As a form of programmed cell death (PCD), HR is believed to help plants defend themselves against pathogens by limiting their growth. One of the earliest events in HR is the rapid accumulation of ROS and nitric oxide ${ }^{[36]}$. The development of HR involves a cascade of signaling, during which the earliest changes are generation of reactive oxygen intermediates and rapid intracellular ion fluxes. Subsequently, the downstream protein components involved in cell death execution are activated.

Hypersensitive-induced reaction (HIR) genes are a novel group of plant defense genes associated with the HR. In wheat, two HIR genes, TaHIR1 and TaHIR3, have been identified and found to be upregulated after infection with Pst. Downregulation of TaHIR1 and TaHIR3 reduced resistance in wheat cv. Suwon 11 against the avirulent Pst pathotype CYR23 with reduced area of necrotic cells neighboring the infection sites $^{[37]}$. By virtue of the known PCD mechanism in animals, a series of key components in the cell death pathway of plants have been identified and characterized. BAX inhibitor-1 $(\mathrm{TaBI}-1)^{[38]}$, defender against apoptotic death $(T a D A D 2)^{[39]}$ and monodehydroascorbate reductase $(T a M D A R 6)^{[40]}$ act as negative regulators of PCD in wheat triggered by the Bax gene and Pst. TaDAD2 is presumed to function as a suppressor of cell death in the early stages of wheat-Pst interaction. However, it is dispensable for or has an opposite function in HR or cell death triggered by an avirulent race of Pst at late-infection stages ${ }^{[39]}$. TaBI-1 and TaMDAR6 were significantly upregulated during a compatible wheat-Pst interaction, indicating their contribution to plant susceptibility. Suppression of TaBI-1 or TaMDAR6 enhances wheat resistance to Pst. Notably, the suppression of TaMDAR6 during an incompatible interaction induces a change in the morphology of stomata, which leads to poor stomatal recognition and as a consequence to reduced infection efficiency ${ }^{[40]}$.

Caspases are key components in the animal PCD pathway as the executer of cell death. To date, although no functional homologs of animal caspases have been identified in plants, a family of cysteine-dependent proteases named metacaspases was found in plants, fungi, and protozoans. Metacaspases are cysteine-dependent proteases, which share a complex regulation system with other cell death proteases, such as vacuolar processing enzyme and subtilisin-like serine proteases due to their mutual substrates and related signaling pathways. Metacaspases are divided into two types (type I and type II) according to the structural feature of the linker between the P20-like and P10-like domains ${ }^{[41]}$. The specific roles of different types of metacaspases in plant resistance to a pathogen are largely unknown and debatable. In wheat, a type II metacaspase, TaMCA4, failed to induce PCD directly, but enhanced cell death triggered by Bax or a candidate Pst effector. TaMCA4 accumulates in the incompatible wheat- $P s t$ interaction and functions in the HR triggered in host plants infected by $P s t$, with a reduced necrotic area at infection sites and enhanced susceptibility of wheat cv. Suwon 11 to an avirulent race of Pst in TaMCA4 knockdown wheat seedlings ${ }^{[42]}$.

Numerous studies have indicated that the actin cytoskeleton is important in plant basal defense and non-host resistance to various pathogens. Inhibition of actin may suppress plant defense-related responses, such as papilla formation and accumulation of antifungal compounds at fungal penetration sites and allow successful pathogen penetration and the formation of haustoria in non-host plants $^{[43]}$. In wheat, an actin-depolymerizing factor TaADF7 was shown to be significantly induced in incompatible wheat- $P s t$ interaction and suppression of TaADF7 reduced resistance of wheat to avirulent races of Pst with decreased ROS accumulation and HR. Heterologous overexpression analyses revealed that TaADF7 regulates the actin cytoskeletal dynamics by depolymerizing actin in yeast cells and accelerates the cell death triggered by Bax in tobacco cells. It seems that TaADF7 mainly modulates the dynamics of the actin cytoskeleton to affect ROS accumulation, and then alters subsequent defense responses ${ }^{[4]}$.

\subsubsection{Lesion mimic mutants}

In addition to the HR-induced cell death, a class of lesion mimic (Les/les) mutants is ubiquitous in plants, which develop cell death lesions resembling those of pathogeninduced lesions even in the absence of the pathogen, and thus provide a platform to unravel PCD signaling pathways in plants ${ }^{[45]}$. Lesion mimics are sometimes associated with enhanced disease resistance, including elevated expression of $P R$ genes and other markers of defense system activation. TaLSDI encoding an altered zinc finger protein gene producing a wheat lesion-simulating disease, was able to suppress Bax-triggered PCD in wheat cells, whereas silencing of TaLSD1 enhanced wheat resistance against Pst. This indicates that TaLSDI negatively 
regulates both hypersensitive cell death response and plant resistance to Pst ${ }^{[46]}$. Wheat TaLlsl, the homolog of $\mathrm{PaO}$ that is responsible for the lesion mimic phenotype in maize ${ }^{[47]}$, was presumed to execute a rheostat role in cell death regulation by controlling a delicate threshold to maintain cell homeostasis in adaption to various stress. Downregulation of TaLls1 in wheat did not change the disease symptoms but enhanced tolerance to Pst via a significant increase in $\mathrm{H}_{2} \mathrm{O}_{2}$ generation, causing elevated cell death and upregulation of PRs.

\subsubsection{Pattern recognition receptors}

Plant PRRs are represented by transmembrane receptor like kinases (RLKs) and receptor-like proteins (RLPs). RLKs typically contain extracellular leucine-rich repeat (LRR) domains and intracellular kinase domains, whereas RLPs lack the kinase domain but possess a small cytoplasmic tail ${ }^{[48]}$. Together, the RLK and RLP families comprise a large repertoire of cell surface receptors that recognize a wide variety of activating ligands (including lipids, proteins, nucleic acids and carbohydrates) from various exogenous sources. Due to the availability of genome sequences, many $P R R$ genes have been identified from model species, with 57 predicted $R L P$ genes distributed at 33 loci in Arabidopsis, and 90 RLP genes distributed at 38 loci in rice ${ }^{[49]}$.

In wheat, an important group of light-regulated $R L K$ genes have been identified, including TaRLK-R1, TaRLK$R 2$ and TaRLK-R3 and their homologous WLRK family members, that appear to encode novel proteins that are vital for enabling wheat plants to cope with stress conditions. Reducing the transcript levels of TaRLK-R1, TaRLK-R2 or TaRLK-R3 individually or simultaneously compromised the HR of wheat cv. Suwon 11 to the avirulent races of $P s t$, suggesting that the three wheat $R L K$ genes share a basic function of aiding in the protection of wheat cells against $P s t^{[50]}$. From an applied point of view, the identification of TaRLK-R1, TaRLK-R2 and TaRLK-R3 as positive regulators of the wheat HR response to the stripe rust fungus may provide molecular targets for the development of durable resistance to a pathogen that causes serious losses in wheat crops worldwide.

A novel RLP gene, TaRLP1.1, was characterized as important for defense against Pst, and resulted in suppressed HR and increased susceptibility to Pst in TaRLP1.1-knockdown plants. Moreover, transformation of TaRLP1.1 into the susceptible wheat cv. Yangmai 158 promoted resistance to Pst, and HR was enhanced at the infection sites ${ }^{[51]}$. It was proposed that TaRLP1.1 contributes greatly to HR during pathogen-host interaction. Characterization of TaRLP1.1 may facilitate breeding for stripe rust resistance and lead to a better understanding of the evolution of the $R L P$ genes in wheat.

\subsubsection{Heat shock proteins}

ETI expression in higher plants is known to be mediated by recognition of $R$ genes and $A v r$ genes. Many $\mathrm{R}$ proteins have been found to be functionally dependent on cytosolic Hsp90s. The Arabidopsis R protein RPM1 mediating the hypersensitive resistance response to Pseudomonas syringaepv. tomato strain DC3000 was identified as a client of cytosolic Hsp90s ${ }^{[52]}$. Furthermore, cytosolic Hsp90s have been found to interact with two co-chaperones, SGT1 and RAR1, that are major regulatory components of disease resistance triggered by many $\mathrm{R}$ proteins in both dicotyledonous and monocotyledonous plants ${ }^{[53]}$. In wheat, three Hsp90 genes have been identified, among which TaHsp90.1 genes exhibited higher transcript levels in the stamen than in the leaf, culm and root, and TaHsp90.2 and TaHsp 90.3 were more ubiquitously transcribed in the vegetative and reproductive organs examined. Decreasing the expression of TaHsp 90.1 genes by VIGS caused pronounced inhibition of wheat seedling growth, whereas the suppression of TaHsp90.2 or TaHsp90.3 genes compromised HR of the wheat cv. Suwon 11 to Pst ${ }^{[54]}$. The first systematic determination of wheat genes encoding cytosolic Hsp90s provides useful evidence for the functional involvement of cytosolic Hsp90s in the control of seedling growth and disease resistance in common wheat.

\subsubsection{SNAREs}

SNAREs (soluble N-ethylmaleimide-sensitive factor attachment protein receptors) are key components of vesicle trafficking in eukaryotic cells ${ }^{[55]}$. Several SNARE genes in plants have been shown to be involved in plant resistance against various pathogens by mediating trafficking of defense-responsive compounds. For example, HvSNAP34 in barley (Hordeum vulgare) participates in callose deposition during non-host resistance to powdery mildew ${ }^{[56]}$. A family of SNARE genes that have no homologs in mammalian or yeast genomes was found to exist in plants, called the Novel Plant SNARE (NPSN) genes. AtNPSN11 was reported to be involved in one of the two KNOLLE-containing tetrameric SNARE complexes, which jointly mediate membrane fusion during cytokinesis $^{[57]}$. In wheat, three NPSNs (TaNPSN11, TaNPSN12 and TaNPSN13) and three plant defense-related SNARE homologs (TaSYP132, TaSNAP34 and TaMEMB12) have been identified. Owing to the reduced resistance toward Pst in TaSYP132-knockdown plants and its ability to interact with TaNPSN11, TaSYP132 was predicted to function as a complex with TaNPSN11 in the host response to pathogens. The primary localization of TaNPSN11 on vesicle structures near the plasma membrane facing the $P s t$ infection sites and the subsequent 
activation of vesicle transport to the infection sites indicated a role for TaNPSN11 in vesicle trafficking between the Golgi apparatus and plasma membrane, possibly involving the transport of plant defense-related materials ${ }^{[58]}$.

\subsection{Signaling pathway}

Plants have evolved multiple signaling pathways to establish arrays of physiological and biochemical processes to overcome various biotic and abiotic stresses, including cold, drought, salinity and pathogen infection. Upon infection by Pst, ion exchange takes place from the wheat cell plasma membranes, with release of calcium ions, production of a large quantity of reactive oxygen species and phosphorylated proteins, and activation of a series of defense-related genes. All these activities have been shown to be closely interlinked by signal transduction pathways.

Calcium is a ubiquitous and essential secondary messenger in eukaryotic signal transduction pathways. Calcium binding protein is an important component of the signal transduction pathways and plays various roles in plant response to biotic and abiotic stresses, as well as in plant developmental processes. A recent report showed that $T a C a b 1$, encoding a calcium binding EF-hand protein, is upregulated in wheat leaves treated with various phytohormones (abscisic acid, benzyl adenine, ethylene, methyl jasmonate and SA) or under different stress stimuli (wounding, low temperature, polyethylene glycol or high salinity $)^{[59]}$. More importantly, TaCabl was shown to be important in regulating wheat basic resistance to the stripe rust fungus with similar induction and expression pattern in both compatible and incompatible interactions. Transcription analyses suggested that $\mathrm{TaCab} 1$ is involved in plant-pathogen recognition, and that basal tolerance to biotic and abiotic stresses is accomplished mainly through the SA signaling pathway ${ }^{[59]}$. The majority of the $\mathrm{Ca}^{2+}$ sensor proteins contain a conserved calcium-dependent membrane-targetingmodule (C2 domain). TaERG3, a novel C2 domain protein, is upregulated by applied $\mathrm{CaCl}_{2}$ and assumed to be involved in wheat defense responses against the stripe rust fungus involving an abscisic acid-dependent signaling pathway, due to the dramatic induction of its expression by $P s t$ and exogenous abscisic acid ${ }^{[60]}$. Thus, it seems that wheat deploys diverse sensors to perceive the $\mathrm{Ca}^{2+}$ signals and then activates the appropriate downstream defense pathways.

Small GTP binding proteins are monomeric G proteins constituting a superfamily consisting of at least five families (Ras, Rho, Rab, Sar1/Arf and Ran). The Rab proteins, belonging to the small guanosine triphosphatases (GTPases) superfamily, are thought to act as molecular switches, which play an essential role in both endocytic and exocytic traffic in eukaryotic cells. Rab7 is regarded as a key regulator in endo-lysosomal trafficking, which mediates the regulated internalization and degradation of nutrient transporters and triggers nutrient starvation that facilitates cell death ${ }^{[61]}$. In Arabidopsis, overexpression of the Rab7 homolog RabG3b leads to expanded HR upon pathogen infection and accelerated leaf senescence ${ }^{[62]}$. A wheat Rab7 homolog TaRab7 was identified and observed to be upregulated in response to salt and drought stress, and infection by the stripe rust fungus, indicating that $T a R a b 7$ has a role in plant response to various biotic and abiotic stimuli $^{[63]}$. Reduced resistance of wheat to avirulent $P s t$ race CYR23 in TaRab7 knockdown plants further proved the involvement of TaRab7 in wheat defense against Pst ${ }^{[63]}$.

\subsection{Transcription}

Transcription factors (TFs) bind to specific regulatory sites upstream of genes in a regulatory network by direct physical interaction or in combination with other proteins to respond to developmental or environmental stimuli to regulate gene expression in response to a signaling cascade. In plants, more than 50 families of TFs have been identified based on sequence analysis in Arabidopsis and rice. Among these TFs, members of the NAC, WRKY, $\mathrm{C} 2 \mathrm{H} 2$-type zinc finger, Apetala2/ethylene-responsive element binding protein (AP2/EREBP) and MYB families have been well characterized for their regulatory roles in plant stress and defense responses ${ }^{[64]}$.

NAC proteins constitute one of the largest families of plant-specific TFs and are known to possess diverse roles in plant development and responses to environmental stimuli. In recent years, increasing evidence has implicated some NAC genes in plant defense response to pathogen infection and environmental stimuli, particularly the genes in the ATAF subfamily. Overexpression of OsNAC4 resulted in HR cell death, and in OsNAC4 knockdown lines, HR cell death was markedly decreased in response to avirulent bacterial strains (Acidovorax avenae $\mathrm{N} 1141)^{[65]}$. In wheat, two novel NAC transcription factors TaNAC4 ${ }^{[66]}$ and $T a N A C 8^{[67]}$ were isolated from a wheat-Pst cDNA library and both were upregulated upon infection by an avirulent $P$ st race, suggesting that they may be involved in wheat defense to Pst infection. Also, expression of the two transcription factors was induced by exogenously applied methyl jasmonate and ethylene, and environmental stimuli including high salinity, wounding, or low-temperature. These results indicate that these two NAC protein genes function as a transcriptional activator involved in wheat response to biotic and abiotic stresses.

MYB proteins are key factors in the regulatory networks of a number of processes, including the determination of cell shape and organ development. More than 20 years ago, the first plant MYB gene $\mathrm{C} 1$ encoding a c-MYB-like transcription factor, was identified in maize (Zea mays) and was found to be involved in anthocyanin biosynthesis ${ }^{[68]}$. The wheat MYB gene TaMYB4 was shown to be induced 
by various phytohormones or under different stimuli ${ }^{[69]}$. It is significantly upregulated in the early stage at $48 \mathrm{~h}$ after inoculation with an incompatible Pst race. Furthermore, silencing of TaMYB4 enhances the susceptibility of wheat $\mathrm{cv}$. Suwon 11 to an avirulent $P s t$ race, indicating that TaMYB4 has a role in the wheat response to biotic stress $^{[69]}$. A novel $b Z I P$ gene from wheat, designated as TabZIP1,was rapidly and strongly induced during an incompatible wheat-Pst interactions ${ }^{[70]}$ and by exogenously applied methyl jasmonate and ethylene. Treatment with both of these, but not SA, could induce TabZIP1 expression, indicating that the TabZIP1 may be involved in defense response to stripe rust fungus infection through the jasmonate/ethylene-dependent signal transduction pathways ${ }^{[70]}$.

In recent years, increasing evidence has implicated EIN3 family genes in defense responses to pathogen attack and environmental stimuli. EIN3 is a key TF in the ethylene signaling pathway, which also functions as positive regulators of a subset of jasmonic acid responses, including $P R$ gene expression, plant resistance to necrotrophic fungi and root development. These results suggest that EIN3/ EILs participate in stress responses not only via ethylene signaling, but also via jasmonate signaling. A recent report showed that EIN3/EILs are also involved in the regulation of plant innate immunity via the SA signaling pathway ${ }^{[71]}$. In wheat, the TaEIL1 transcript level was upregulated in wheat leaves challenged by virulent Pst race CYR31 but reduced under SA treatment ${ }^{[72]}$. Furthermore, knockdown of TaEIL1 enhanced wheat resistance to Pst, indicating that TaEIL1 might serve as a negative regulator in the wheat defense response through the suppression of the SA pathway ${ }^{[72]}$.

\subsection{Resistance genes ( $\mathrm{Yr} 10, \mathrm{Yr} 18$ and $\mathrm{Yr} 36)$}

During the coevolution of plants and pathogens, plants have acquired a repertoire of $R$ genes to protect them from diseases. Although numerous disease resistance genes have been recently isolated in dicots, only a few have been reported in monocots. More than 50 stripe rust resistance genes have been documented in wheat, but only three of them have been obtained using the map-based cloning. The stripe rust resistance gene $\mathrm{Yr} 10$ is the first $R$ gene cloned from wheat, encoding a CC-NBS-LRR protein and locating on chromosome 1B in Moro and originates from the Turkish line PI $178383^{[73]}$. Lr34/Yr18 has supported resistance to rusts and powdery mildews for more than 50 years, and is now shared by wheat cultivars around the world. In 2009 the $L r 34 / Y r 18$ gene was cloned and shown to encode a protein that resembled adenosine triphosphate binding cassette transporters of the pleiotropic drug resistance subfamily. The $\operatorname{Lr} 34 / \mathrm{Yr} 18$ gene stimulates senescence-like processes in the flag leaf tips and edges, and confers resistance on adult wheat plants ${ }^{[74]}$. Yr36 (WKS1) confers broad-race resistance to stripe rust at relatively high temperatures $\left(25-35^{\circ} \mathrm{C}\right)$. The protein contains a kinase domain and a putative START lipid binding domain. Analysis of five independent mutations and transgenic complementation confirmed that both domains are necessary to confer resistance to the wheat stripe rust fungus ${ }^{[75]}$. $\operatorname{Yr} 36$ is present in wild wheat but absent in modern bread wheat cultivars, and therefore, can now be used to improve resistance to the stripe rust fungus in a broad set of cultivars.

\subsection{Role of microRNA in wheat defense to Pst}

MicroRNAs (miRNAs) have emerged as important posttranscriptional regulators in plant stress responses. At present, RNA sequencing, microarrays and RNA gel blot analysis have been used to detect novel miRNAs. Moreover, degradome sequencing and cotransformation technology in tobacco leaves have been used to identify the targets of plant miRNAs ${ }^{[76]}$. Accumulation of the wheat miRNA tae-miR408 following Pst infection leads to negative regulation of plantacyanin-like (basic blue) protein TaCLP, which results in reduced resistance of wheat to $P s t^{[77]}$. The wheat miRNAtae-miR159a can cleavage mRNA for TaMyb3 transcription factor from the MYB subfamily of wheat, which is important in regulation of wheat resistance to $P s t^{[78]}$. In addition, two novel wheat miRNAs (1136-P3 and PN-2013) were isolated and identified as cleaving mRNA from a monodehydroascorbate reductase gene TaMDHAR, an important gene in the ascorbate-glutathione cycle ${ }^{[79]}$. However, only accumulation of PN-2013 downregulated the expression of TaMDHAR in Xingzi 9104 and further resulted in enhanced resistance of wheat to $P s t$ at adult stages ${ }^{[79]}$. The specific role of miRNAs in wheat resistance to Pst is still largely unknown, but the examples above indicates that wheat possesses a regulatory network that integrates miRNA function to regulate immunity against Pst.

\section{Varying pathogenicity of Puccinia strifformis}

\subsection{Genomic and transcriptomic tools for analyzing the pathogenicity of Pst}

To date, no stable transformation system has been established for Pst and other Pucciniales. The obligate biotrophic nature further hampers molecular and genetic studies of the important fungus, resulting in narrow and limited knowledge of genomes and genes involved in the biology and pathogenicity of the pathogens. To overcome this limitation, transcriptomic tools has been applied to the dissection of pathogenicity of these types of pathogens. A series of cDNA libraries were developed from different stages of Pst development, including ungerminated and 
germinated urediniospores and haustoria. In 2007, a fulllength cDNA library, consisting of 42240 clones was constructed using urediniospores of race PST-78 of Pst, from which 51 different genes encoding proteins that are involved in amino acid metabolism, cell defense, cell cycle, cell signaling, cell structure and growth, energy cycle, lipid and nucleotide metabolism, protein modification, the ribosomal protein complex, sugar metabolism, transcription factors, transport of metabolites, and virulence/infection were identified ${ }^{[80]}$. In a germinated urediniospores cDNA library, a total of 4798 ESTs were sequenced to generate 1118 unisequences, among which several fungal pathogenicity or virulence factors were identified, such as HESP767 of the flax rust and PMK1 of the rice blast fungus ${ }^{[81]}$. Importantly, the haustoria of Pst were isolated successfully, which enhanced the identification of the pathogenicity genes during the infection process. From this library, 15 genes encoding putative secreted proteins and six genes induced during the infection process were obtained, which provided candidates for further studies to determine their functions in wheat-Pst interactions ${ }^{[82]}$. Gene sets obtained from these different libraries appeared to be remarkably different, suggesting drastic reprogramming of the transcriptome during these different processes ${ }^{[83]}$. Genes upregulated in germinated spores were involved in processes involving cell proliferation, such as cell cycle control and DNA and cell wall metabolism, whereas in haustoria were more engaged in energy production and biosynthetic processes.

The ability to determine the sequence of fungal genomes, together with transcriptomics, has enabled unprecedented insights into genome composition, structure, and plasticity as well as genome evolution and adaptation of Pst. Next generation sequencing with its high efficiency has allowed rapid advances in the study of rust genomes. Cantu et al. ${ }^{[84]}$ used Illumina sequencing to assemble a draft genome of Pst isolate 130 consisting of about 29178 contigs $(64.8 \mathrm{Mb})$, covering an estimated minimum of $88 \%$ of Pst genes, and annotating 22815 putative coding sequences. Pst is a dikaryotic rust fungus and Zheng et al. ${ }^{[85]}$ used a fosmid-to-fosmid sequencing strategy to generate a significantly improved draft genome (about $110 \mathrm{Mb}$ ) of a Chinese Pst isolate CYR32. This strategy combined the use of a fosmid library and Illumina sequencing, which have a great advantage over older sequencing strategies for analyzing dikaryotic genomes. Genomic features compared to those of other saprotrophic and symbiotic fungi indicated that the Pst genome, like those of Puccinia graminis f. sp. tritici (Pgt) and Melampsora larici-populina (Mlp), have a large expansion of effector-like small secreted proteins and amino acid transporters. However, it lacks genes for sucrose transporters, and nitrogen and sulfur assimilation pathways. This deficiency might be one reason for their obligate biotrophic lifestyle. In addition, resequencing of six isolates from different continents suggests that genetic recombination may contribute more to Pst virulence variation than geographical origin ${ }^{[85]}$.

\subsection{Secretome}

Effectors are of special importance to obligate biotrophs, such as the rust fungi. Generally, protein effectors are secreted via the conventional endoplasmic reticulum-Golgi apparatus route, which requires the $\mathrm{N}$-terminal secretion signal. Based on this feature, a total of 2092 proteins encoded by the Pst genome were predicted by SignalP, TargetP and TMHMM computer programs, which accounts for $8.3 \%$ of the total number of proteins ${ }^{[85,86]}$, and similarly the genomes of Pgt and Mlp were predicted to encode 1459 and 1178 secreted proteins, respectively. In comparison to non-rust fungal pathogens, Pst, Pgt and Mlp appear to have a relatively larger (higher percentage) secretome. The availability of genome sequences of these three rust fungi has enabled the prediction and identification of large sets of effector, and Saunders et al. ${ }^{[87]}$ described the informatics analysis of putative rust effectors. No systematic screening for effectors in cereal rusts has been undertaken, however, and with such a large number of secreted proteins, it is a major challenge to identify effectors in the wheat rust fungi without a transformation system.

To date, only six effector proteins have been identified in three different rust species: AvrM, AvrL567, AvrP123, and AvrP4 in the flax rust fungus Melampsora lini ${ }^{[88,89]}$, RTP1 in the bean rust fungus Uromyces viciae-fabae var. viciaefabae ${ }^{[90]}$, and PGTAUSPE-10-1 in the wheat stem rust fungus $P g t^{[91]}$. All of these proteins are thought to be translocated from haustoria to the host cell. The four flax rust effectors were identified by their avirulence function to the corresponding flax $R$ gene. Indirect evidence has confirmed that AvrL567 and AvrM could translocate to the plant cell and are active intracellularly during the infection in the absence of the pathogen. The AvrL567 genes are expressed in rust haustoria but their corresponding proteins are recognized inside the plant cells. A hydrophobic surface patch is required for entry into plant cells by AvrM, whereas the $\mathrm{C}$-terminal coiled-coil domain mediates interaction with the resistance protein $\mathrm{M}$ through multiple contact points ${ }^{[92]}$. Immunocytological and biochemical studies indicated that RTP1 is a member of a new class of structural effectors, which are capable of forming filamentous structures in vitro and in vivo ${ }^{[93]}$. Due to the induction of cell death in the host line carrying the resistance gene Sr22, PGTAUSPE-10-1 was considered as a candidate AvrSr22 ${ }^{[91]}$.

Apart from the six rust effectors, only a few secreted proteins have been cloned as candidate effectors on the basis of expressed sequence tags and cDNA library from Pst. Dong et al. ${ }^{[94]}$ cloned three Pst-specific genes encoding secreted proteins with much higher expression levels in infected leaves than in germinated and ungermi- 
nated urediniospores, and these may be good candidates for effectors. In addition, $\mathrm{Gu}$ et al. ${ }^{[95]}$ reported that the Ps87 gene from Pst encodes a secreted protein that is conserved in diverse fungal pathogens. Ps87 contains an RXLR-like motif and could utilize similar translocation machinery to those of oomycete and fungal pathogens in plant cells. However, no direct suppression activity of plant defense responses was detected for Ps87.

\subsection{Pathogenicity-related genes}

In recent years, some Pst genes have been identified because of their effects on pathogenicity. Guo et al. ${ }^{[96]}$ identified and characterized the first Pst MAPK gene PsMAPK1. Using heterologous systems, they confirmed that PSMAPK1 may contribute to the penetration and colonization of Pst. Host-induced gene silencing (HIGS) is a newly developed RNAi technology to indirectly silence parasite genes by expressing an RNAi construct in vivo in the host. Yin et al. ${ }^{[97]}$ developed a barley stripe mosaic virus-based HIGS approach for identifying gene function in Pst. Zhang et al. ${ }^{[98]}$ identified and characterized the calcineurin genes $P_{s} C N A 1$ and $P_{s} C N B 1$ that contribute to morphogenetic differentiation and the production of urediniospores by HIGS. Cheng et al. ${ }^{[99]}$ reported an in planta highly induced $P K$ gene PSSRPKL that is specific to cereal rust fungi. By using HIGS and heterologous expression, PSSRPKL was shown to be an important pathogenicity factor responsible for fungal growth that responds to environmental stresses. Recently, an adenine nucleotide translocase, PsANT, was shown to contribute to the growth and development of Pst due to its role in energy supply. And furthermore, PsANT was observed to be involved in the regulation of apoptosis in the wheat stripe rust fungus ${ }^{[100]}$.

\section{Conclusions}

During the coevolution of wheat and $P s t$, challenged by the rapid change in the virulence of $P s t$, wheat has acquired many traits to defend itself against new virulent $P s t$ races. Obligate parasitic fungi, such as Pst, have adapted to colonize new hosts and different tissue types, and to overcome host defense responses. This review has summarized recent discoveries in the pathogen's invasion strategy and the host's defense responses through histological and cytological studies. Moreover, advances in understanding the molecular events that underlying the resistance of wheat and the pathogenicity of Pst were discussed. Understanding these mechanisms is instrumental for designing novel management strategies for wheat stripe rust disease. The extremely sophisticated regulatory networks in wheat defense responses and the expanding reservoirs of effectors will require us to identify the most essential targets for genetic resistance or chemical controls.
(1) Wheat interaction with the rust fungus, Pst, which threatens global food security, is a good model for understanding the mechanisms of the pathogen virulence and host resistance to rust fungi.

(2) The obligate parasitic nature drives the rapid variation in virulence of Pst and the evolution of wheat's defenses against the pathogenicity of the fungus.

(3) During the coevolution, host plants acquire various biological processes, such as the metabolism, signal transduction, transcription regulation, activation of defense response, and microRNAs molecules, to form complicated and delicate regulatory networks to defend against pathogens.

(4) To survive and reproduce, rust fungi form a specialized infection structure, the haustorium, to absorb nutrients and energy from host cells, and to secrete many effectors to inhibit PTI and/or ETI to promote their growth and development. It should be a priority to elucidate why highly specialized haustoria are needed in this pathosystem.

Acknowledgements We thank Dr. Ralf T. Voegele from the University of Hohenheim for his helpful advice. This work was supported by grants from the National Basic Research Program of China (2013CB127700), the National Natural Science Foundation of China (31401693), and the China Postdoctoral Science Foundation (2014M550514).

Compliance with ethics guidelines Chunlei Tang, Xiaojie Wang, Yulin Cheng, Minjie Liu, Mengxin Zhao, Jinping Wei, and Zhensheng Kang declare that they have no conflict of interest or financial conflicts to disclose.

This article does not contain any studies with human or animal subjects performed by any of the authors.

\section{References}

1. Chen X. Epidemiology and control of stripe rust [Puccinia striiformis f. sp. tritici] on wheat. Canadian Journal of Plant Pathology, 2005, 27(3): 314-337

2. Saari EE, Prescott J. World distribution in relation to economic losses. The Cereal Rusts, 1985, 2(1): 259-298

3. Chen W, Wu L, Liu T, Xu S, Jin S, Peng Y, Wang B. Race dynamics, diversity, and virulence evolution in Puccinia striiformis $\mathrm{f}$. sp. tritici, the causal agent of wheat stripe rust in China from 2003 to 2007. Plant Disease, 2009, 93(11): 1093-1101

4. Jones J D, Dangl J L. The plant immune system. Nature, 2006, 444 (7117): 323-329

5. Jin Y, Szabo L J, Carson M. Century-old mystery of Puccinia striiformis life history solved with the identification of Berberis as an alternate host. Phytopathology, 2010, 100(5): 432-435

6. Zhao J, Wang L, Wang Z, Chen X, Zhang H, Yao J, Zhan G, Chen W, Huang L, Kang Z. Identification of eighteen Berberis species as alternate hosts of Puccinia striiformis f. sp. tritici and virulence variation in the pathogen isolates from natural infection of barberry plants in China. Phytopathology, 2013, 103(9): 927-934

7. Kang Z, Li Z, Shang H, Chong J, Rohringer R. Ultrastructure of haustorial mother cell of wheat stripe rust. Acta Mycologica Sinica, 
1993, 13(3): 206-210 (in Chinese)

8. Voegele R T, Mendgen K. Rust haustoria: nutrient uptake and beyond. New Phytologist, 2003, 159(1): 93-100

9. Zhang H, Han Q, Wang C, Huang L, Zhang Q, Kang Z. Histology and ultrastructure of resistant mechanism of a new wheat material-Yilipu to Puccinia striiformis. Acta Phytopathologica Sinica, 2008, 38(2): 153-164 (in Chinese)

10. Kang Z, Huang L, Buchenauer H. Ultrastructural changes and localization of lignin and callose in compatible and incompatible interactions between wheat and Puccinia striiformis. Journal of Plant Diseases and Protection, 2002, 109(1): 25-37

11. Zhang H, Wang C, Cheng Y, Chen X, Han Q, Huang L, Wei G, Kang Z. Histological and cytological characterization of adult plant resistance to wheat stripe rust. Plant Cell Reports, 2012, 31(12): 2121-2137

12. Mysore K S, Ryu C M. Nonhost resistance: how much do we know? Trends in Plant Science, 2004, 9(2): 97-104

13. Cheng Y, Zhang H, Yao J, Wang X, Xu J, Han Q, Wei G, Huang L, Kang Z. Characterization of non-host resistance in broad bean to the wheat stripe rust pathogen. BMC Plant Biology, 2012, 12(1): 96

14. Cheng Y, Zhang H, Yao J, Han Q, Wang X, Huang L, Kang Z. Cytological and molecular characterization of non-host resistance in Arabidopsis thaliana against wheat stripe rust. Plant Physiology and Biochemistry, 2013, 62: 11-18

15. Yang Y, Zhao J, Xing H, Wang J, Zhou K, Zhan G, Zhang H, Kang Z. Different non-host resistance responses of two rice subspecies, japonica and indica, to Puccinia striiformis f. sp. tritici. Plant Cell Reports, 2014, 33(3): 423-433

16. Kang Z, Huang L, Buchenauer H. Subcellular localization of chitinase and $\beta-1,3$-glucanase in compatible and incompatible interactions between wheat and Puccinia striiformis f. sp. tritici. Journal of Plant Diseases and Protection, 2003, 110(2): 170-183

17. Kang Z, Wang Y, Huang L, Wei G, Zhao J. Histology and ultrastructure of incompatible combination between Puccinia striiformis and wheat cultivars with resistance of low reaction type. Scientia Agricultura Sinica, 2003, 36(9): 1026-1031 (in Chinese)

18. Wang C F, Huang L L, Buchenauer H, Han Q M, Zhang H C, Kang $\mathrm{Z} \mathrm{S}$. Histochemical studies on the accumulation of reactive oxygen species $\left(\mathrm{O}_{2}^{-}\right.$and $\left.\mathrm{H}_{2} \mathrm{O}_{2}\right)$ in the incompatible and compatible interaction of wheat: Puccinia striiformis f. sp. tritici. Physiological and Molecular Plant Pathology, 2007, 71(4-6): 230-239

19. Ma J, Huang X, Wang X, Chen X, Qu Z, Huang L, Kang Z. Identification of expressed genes during compatible interaction between stripe rust (Puccinia striiformis) and wheat using a cDNA library. BMC Genomics, 2009, 10(1): 586

20. Wang X, Liu W, Chen X, Tang C, Dong Y, Ma J, Huang X, Wei G, Han Q, Huang L, Kang Z. Differential gene expression in incompatible interaction between wheat and stripe rust fungus revealed by cDNA-AFLP and comparison to compatible interaction. BMC Plant Biology, 2010, 10(1): 9

21. Wang X, Tang C, Zhang G, Li Y, Wang C, Liu B, Qu Z, Zhao J, Han Q, Huang L, Chen X, Kang Z. cDNA-AFLP analysis reveals differential gene expression in compatible interaction of wheat challenged with Puccinia striiformis f. sp. tritici. BMC Genomics,
2009, 10(1): 289

22. Moldenhauer J, Pretorius Z A, Moerschbacher B M, Prins R, Van Der Westhuizen A J. Histopathology and PR-protein markers provide insight into adult plant resistance to stripe rust of wheat. Molecular Plant Pathology, 2008, 9(2): 137-145

23. Coram T E, Settles M L, Chen X. Transcriptome analysis of hightemperature adult-plant resistance conditioned by Yr39 during the wheat-Puccinia striiformis f. sp. tritici interaction. Molecular Plant Pathology, 2008, 9(4): 479-493

24. Huang X, Yu X, Qu Z, Wang X, Han Q, Huang L, Kang Z. Construction of suppression subtractive hybridization cDNA library of wheat adult plant resistance to stripe rust and analysis of its expressed sequence tags. Journal of Agricultural Biotechnology, 2007, 15(6): 976-981 (in Chinese)

25. Xu L, Jia J, Lv J, Liang X, Han D, Huang L, Kang Z. Characterization of the expression profile of a wheat acireductone-dioxygenase-like gene in response to stripe rust pathogen infection and abiotic stresses. Plant Physiology and Biochemistry, 2010, 48(6): 461-468

26. Yu X, Wang X, Huang X, Buchenauer H, Han Q, Guo J, Zhao J, Qu Z, Huang L, Kang Z. Cloning and characterization of a wheat neutral ceramidase gene Ta-CDase. Molecular Biology Reports, 2011, 38(5): 3447-3454

27. Duan Y H, Guo J, Wang S J, Yu X M, Huang L L, Kang A S. Cloning and expression analysis of alanine aminotransferase gene TaAlaAT1 in wheat infected with stripe rust fungus. Acta Phytopathologica Sinica, 2009, 39(2): 139-146 (in Chinese)

28. Scofield S R, Huang L, Brandt A S, Gill B S. Development of a virus-induced gene-silencing system for hexaploid wheat and its use in functional analysis of the $L r 21$-mediated leaf rust resistance pathway. Plant Physiology, 2005, 138(4): 2165-2173

29. Nandi A, Welti R, Shah J. The Arabidopsis thaliana dihydroxyacetone phosphate reductase gene SUPPRESSSOR OF FATTY ACID DESATURASE DEFICIENCY1 is required for glycerolipid metabolism and for the activation of systemic acquired resistance. Plant Cell, 2004, 16(2): 465-477

30. Yang Y, Zhao J, Liu P, Xing H, Li C, Wei G, Kang Z. Glycerol-3phosphate metabolism in wheat contributes to systemic acquired resistance against Puccinia striiformis f. sp. tritici. PLoS ONE, 2013, 8(11): e81756

31. Tang C, Wang X, Duan X, Wang X, Huang L, Kang Z. Functions of the lethal leaf-spot 1 gene in wheat cell death and disease tolerance to Puccinia striiformis. Journal of Experimental Botany, 2013, 64(10): 2955-2969

32. Feng H, Liu W, Zhang Q, Wang X, Wang X, Duan X, Li F, Huang L, Kang Z. TaMDHAR4, a monodehydroascorbate reductase gene participates in the interactions between wheat and Puccinia striiformis f. sp. tritici. Plant Physiology and Biochemistry, 2014, 76: 7-16

33. Wang X, Tang C, Deng L, Cai G, Liu X, Liu B, Han Q, Buchenauer H, Wei G, Han D, Huang L, Kang Z. Characterization of a pathogenesis-related thaumatin-like protein gene TaPR5 from wheat induced by stripe rust fungus. Physiologia Plantarum, 2010, 139(1): 27-38

34. Liu B, Xue X, Cui S, Zhang X, Han Q, Zhu L, Liang X, Wang X, Huang L, Chen X, Kang Z. Cloning and characterization of a wheat 
$\beta$-1,3-glucanase gene induced by the stripe rust pathogen Puccinia striiformis f. sp. tritici. Molecular Biology Reports, 2010, 37(2): $1045-1052$

35. Zhang G, Li Y M, Zhang Y, Dong Y L, Wang X J, Wei G R, Huang L L, Kang Z S. Cloning and characterization of a pathogenesisrelated protein gene TaPR10 from wheat induced by stripe rust pathogen. Agricultural Sciences in China, 2010, 9(4): 549-556 (in Chinese)

36. Chandok M R, Ytterberg A J, van Wijk K J, Klessig D F. The pathogen-inducible nitric oxide synthase (iNOS) in plants is a variant of the $P$ protein of the glycine decarboxylase complex. Cell, 2003, 113(4): 469-482

37. Duan Y, Guo J, Shi X, Guan X, Liu F, Bai P, Huang L, Kang Z. Wheat hypersensitive-induced reaction genes TaHIR1 and TaHIR3 are involved in response to stripe rust fungus infection and abiotic stresses. Plant Cell Reports, 2013, 32(2): 273-283

38. Wang X, Tang C, Huang X, Li F, Chen X, Zhang G, Sun Y, Han D, Kang Z. Wheat BAX inhibitor-1 contributes to wheat resistance to Puccinia striiformis. Journal of Experimental Botany, 2012, 63 (12): 4571-4584

39. Wang X, Tang C, Zhang H, Xu J R, Liu B, Lv J, Han D, Huang L, Kang Z. TaDAD2, a negative regulator of programmed cell death, is important for the interaction between wheat and the stripe rust fungus. Molecular Plant-Microbe Interactions, 2011, 24(1): 79-90

40. Abou-Attia M A, Wang X, Al-Attala M N, Xu Q, Zhan G, Kang Z. TaMDAR6 acts as a negative regulator of plant cell death and participates indirectly in stomatal regulation during the wheatstripe rust fungus interaction. Physiologia Plantarum, 2015

41. Rahman M. Biochemical analysis of type II Metacaspase (mcIIPa). Dissertation for the Master Degree. Sweden: Uppsala Universitys, 2010

42. Wang X, Wang X, Feng H, Tang C, Bai P, Wei G, Huang L, Kang Z. TaMCA4, a novel wheat metacaspase gene functions in programmed cell death induced by the fungal pathogen Puccinia striiformis f. sp. tritici. Molecular Plant-Microbe Interactions, 2012, 25(6): 755-764

43. Shimada C, Lipka V, O'Connell R, Okuno T, Schulze-Lefert P, Takano Y. Nonhost resistance in Arabidopsis-Colletotrichum interactions acts at the cell periphery and requires actin filament function. Molecular Plant-Microbe Interactions, 2006, 19(3): 270-279

44. Fu Y, Duan X, Tang C, Li X, Voegele R T, Wang X, Wei G, Kang Z. TaADF7, an actin-depolymerizing factor, contributes to wheat resistance against Puccinia striiformis f. sp. tritici. Plant Journal, 2014, 78(1): 16-30

45. Lorrain S, Vailleau F, Balagué C, Roby D. Lesion mimic mutants: keys for deciphering cell death and defense pathways in plants? Trends in Plant Science, 2003, 8(6): 263-271

46. Guo J, Bai P, Yang Q, Liu F, Wang X, Huang L, Kang Z. Wheat zinc finger protein TaLSD1, a negative regulator of programmed cell death, is involved in wheat resistance against stripe rust fungus. Plant Physiology and Biochemistry, 2013, 71: 164-172

47. Gray J, Janick-Buckner D, Buckner B, Close P S, Johal G S. Lightdependent death of maize lls 1 cells is mediated by mature chloroplasts. Plant Physiology, 2002, 130(4): 1894-1907

48. Kruijt M, DE Kock M J, de Wit P J. Receptor-like proteins involved in plant disease resistance. Molecular Plant Pathology, 2005, 6(1): 85-97

49. Wang G, Ellendorff U, Kemp B, Mansfield J W, Forsyth A, Mitchell K, Bastas K, Liu C M, Woods-Tör A, Zipfel C, de Wit P J, Jones J D, Tör M, Thomma B P. A genome-wide functional investigation into the roles of receptor-like proteins in Arabidopsis. Plant Physiology, 2008, 147(2): 503-517

50. Zhou H, Li S, Deng Z, Wang X, Chen T, Zhang J, Chen S, Ling H, Zhang A, Wang D, Zhang X. Molecular analysis of three new receptor-like kinase genes from hexaploid wheat and evidence for their participation in the wheat hypersensitive response to stripe rust fungus infection. The Plant Journal, 2007, 52(3): 420-434

51. Jiang Z, Ge S, Xing L, Han D, Kang Z, Zhang G, Wang X, Wang $\mathrm{X}$, Chen P, Cao A. RLP1.1, a novel wheat receptor-like protein gene, is involved in the defence response against Puccinia striiformis f. sp. tritici. Journal of Experimental Botany, 2013, 64(12): 3735-3746

52. Hubert D A, Tornero P, Belkhadir Y, Krishna P, Takahashi A, Shirasu K, Dangl J L. Cytosolic HSP90 associates with and modulates the Arabidopsis RPM1 disease resistance protein. The EMBO Journal, 2003, 22(21): 5679-5689

53. Botër M, Amigues B, Peart J, Breuer C, Kadota Y, Casais C, Moore G, Kleanthous C, Ochsenbein F, Shirasu K, Guerois R. Structural and functional analysis of SGT1 reveals that its interaction with HSP90 is required for the accumulation of $\mathrm{Rx}$, an R protein involved in plant immunity. Plant Cell, 2007, 19(11): 3791-3804

54. Wang G F, Wei X, Fan R, Zhou H, Wang X, Yu C, Dong L, Dong Z, Wang X, Kang Z, Ling H, Shen Q H, Wang D, Zhang X. Molecular analysis of common wheat genes encoding three types of cytosolic heat shock protein 90 (Hsp90): functional involvement of cytosolic Hsp90s in the control of wheat seedling growth and disease resistance. New Phytologist, 2011, 191(2): 418-431

55. Heese M, Gansel X, Sticher L, Wick P, Grebe M, Granier F, Jürgens G. Functional characterization of the KNOLLE-interacting t-SNARE AtSNAP33 and its role in plant cytokinesis. Journal of Cell Biology, 2001, 155(2): 239-249

56. Inada $\mathrm{N}$, Ueda $\mathrm{T}$. Membrane trafficking pathways and their roles in plant-microbe interactions. Plant \& Cell Physiology, 2014, 55(4): 672-686

57. El Kasmi F, Krause C, Hiller U, Stierhof Y D, Mayer U, Conner L, Kong L, Reichardt I, Sanderfoot A A, Jürgens G. SNARE complexes of different composition jointly mediate membrane fusion in Arabidopsis cytokinesis. Molecular Biology of the Cell, 2013, 24(10): 1593-1601

58. Wang X, Wang X, Deng L, Chang H, Dubcovsky J, Feng H, Han Q, Huang L, Kang Z. Wheat TaNPSN SNARE homologues are involved in vesicle-mediated resistance to stripe rust (Puccinia striiformis f. sp. tritici). Journal of Experimental Botany, 2014, 65 (17): 4807-4820

59. Feng H, Wang X, Sun Y, Wang X, Chen X, Guo J, Duan Y, Huang L, Kang Z. Cloning and characterization of a calcium binding EFhand protein gene $T a C a b 1$ from wheat and its expression in response to Puccinia striiformis f. sp. tritici and abiotic stresses. Molecular Biology Reports, 2011, 38(6): 3857-3866

60. Zhang G, Sun Y, Li Y, Dong Y, Huang X, Yu Y, Wang J, Wang X, 
Wang X, Kang Z. Characterization of a wheat C2 domain protein encoding gene regulated by stripe rust and abiotic stresses. Biologia Plantarum, 2013, 57(4): 701-710

61. Edinger A L, Cinalli R M, Thompson C B. Rab7 prevents growth factor-independent survival by inhibiting cell-autonomous nutrient transporter expression. Developmental Cell, 2003, 5(4): 571-582

62. Kwon S I, Cho H J, Bae K, Jung J H, Jin H C, Park O K. Role of an Arabidopsis Rab GTPase RabG3b in pathogen response and leaf senescence. Journal of Plant Biology, 2009, 52(2): 79-87

63. Liu F, Guo J, Bai P, Duan Y, Wang X, Cheng Y, Feng H, Huang L, Kang Z. Wheat TaRab7 GTPase is part of the signaling pathway in responses to stripe rust and abiotic stimuli. PLOS ONE, 2012, 7(5): e37146

64. Singh K, Foley R C, Oñate-Sánchez L. Transcription factors in plant defense and stress responses. Current Opinion in Plant Biology, 2002, 5(5): 430-436

65. Kaneda T, Taga Y, Takai R, Iwano M, Matsui H, Takayama S, Isogai $\mathrm{A}$, Che $\mathrm{F} \mathrm{S}$. The transcription factor OsNAC4 is a key positive regulator of plant hypersensitive cell death. The EMBO Journal, 2009, 28(7): 926-936

66. Xia N, Zhang G, Liu X Y, Deng L, Cai G L, Zhang Y, Wang X J, Zhao J, Huang L L, Kang Z S. Characterization of a novel wheat NAC transcription factor gene involved in defense response against stripe rust pathogen infection and abiotic stresses. Molecular Biology Reports, 2010, 37(8): 3703-3712

67. Xia N, Zhang G, Sun Y F, Zhu L, Xu L S, Chen X M, Liu B, Yu Y T, Wang X J, Huang L L, Kang Z S. TaNAC8, a novel NAC transcription factor gene in wheat, responds to stripe rust pathogen infection and abiotic stresses. Physiological and Molecular Plant Pathology, 2010, 74(5): 394-402

68. Paz-Ares J, Ghosal D, Wienand U, Peterson P A, Saedler H. The regulatory c1 locus of Zea mays encodes a protein with homology to myb proto-oncogene products and with structural similarities to transcriptional activators. The EMBO Journal, 1987, 6(12): 35533558

69. Al-Attala M N, Wang X, Abou-Attia M A, Duan X, Kang Z. A novel TaMYB4 transcription factor involved in the defence response against Puccinia striiformis f. sp. tritici and abiotic stresses. Plant Molecular Biology, 2014, 84(4-5): 589-603

70. Zhang Y, Zhang G, Xia N, Wang X J, Huang L L, Kang Z S. Cloning and characterization of a bZIP transcription factor gene in wheat and its expression in response to stripe rust pathogen infection and abiotic stresses. Physiological and Molecular Plant Pathology, 2008, 73(4): 88-94

71. Chen H, Xue L, Chintamanani S, Germain H, Lin H, Cui H, Cai R, Zuo J, Tang X, Li X, Guo H, Zhou J M. ETHYLENE INSENSITIVE3 and ETHYLENE INSENSITIVE3-LIKE1 repress SALICYLIC ACID INDUCTION DEFICIENT2 expression to negatively regulate plant innate immunity in Arabidopsis. The Plant Cell, 2009, 21(8): 2527-2540

72. Duan X, Wang X, Fu Y, Tang C, Li X, Cheng Y, Feng H, Huang L, Kang Z. TaEIL1, a wheat homologue of AtEIN3, acts as a negative regulator in the wheat-stripe rust fungus interaction. Molecular Plant Pathology, 2013, 14(7): 728-739

73. Liu W, Frick M, Huel R, Nykiforuk C L, Wang X, Gaudet D A, Eudes F, Conner R L, Kuzyk A, Chen Q, Kang Z, Laroche A. The stripe rust resistance gene $\mathrm{Yr} 10$ encodes an evolutionary-conserved and unique CC-NBS-LRR sequence in wheat. Molecular Plant, 2014, 7(12): 1740-1755

74. Krattinger S G, Lagudah E S, Spielmeyer W, Singh R P, HuertaEspino J, McFadden H, Bossolini E, Selter L L, Keller B. A putative $\mathrm{ABC}$ transporter confers durable resistance to multiple fungal pathogens in wheat. Science, 2009, 323(5919): 1360-1363

75. Fu D, Uauy C, Distelfeld A, Blechl A, Epstein L, Chen X, Sela H, Fahima T, Dubcovsky J. A kinase-START gene confers temperature-dependent resistance to wheat stripe rust. Science, 2009, 323 (5919): 1357-1360

76. Feng H, Sun Y, Wang B, Wang X, Kang Z. Microarray-based identification of conserved microRNA from wheat and their expression profiles response to Puccinia striiformis f. sp. tritici. Canadian Journal of Plant Pathology, 2015, 37(1): 82-91

77. Feng H, Zhang Q, Wang Q, Wang X, Liu J, Li M, Huang L, Kang Z. Target of tae-miR408, a chemocyanin-like protein gene (TaCLP1), plays positive roles in wheat response to high-salinity, heavy cupric stress and stripe rust. Plant Molecular Biology, 2013, 83(4-5): 433-443

78. Feng H, Zhang Q, Li H, Wang X, Wang X, Duan X, Wang B, Kang Z. vsiRNAs derived from the miRNA-generating sites of pri-taemiR159a based on the BSMV system play positive roles in the wheat response to Puccinia striiformis f. sp. tritici through the regulation of taMyb3 expression. Plant Physiology and Biochemistry, 2013, 68: 90-95

79. Feng H, Wang X, Zhang Q, Fu Y, Feng C, Wang B, Huang L, Kang $\mathrm{Z}$. Monodehydroascorbate reductase gene, regulated by the wheat PN-2013 miRNA, contributes to adult wheat plant resistance to stripe rust through ROS metabolism. Biochimica et Biophysica Acta (BBA) - Gene Regulatory Mechanisms, 2014, 1839(1): 1-12

80. Ling $\mathrm{P}$, Wang $\mathrm{M}$, Chen $\mathrm{X}$, Campbell K G. Construction and characterization of a full-length cDNA library for the wheat stripe rust pathogen (Puccinia striiformis f. sp. tritici). BMC Genomics, 2007, 8(1): 145

81. Zhang Y, Qu Z, Zheng W, Liu B, Wang X, Xue X, Xu L, Huang L, Han Q, Zhao J, Kang Z. Stage-specific gene expression during urediniospore germination in Puccinia striiformis f. sp tritici. BMC Genomics, 2008, 9(1): 203

82. Yin C, Chen X, Wang X, Han Q, Kang Z, Hulbert S H. Generation and analysis of expression sequence tags from haustoria of the wheat stripe rust fungus Puccinia striiformis f. sp. Tritici. BMC Genomics, 2009, 10(1): 626

83. Hu G, Linning R, McCallum B, Banks T, Cloutier S, Butterfield Y, Liu J, Kirkpatrick R, Stott J, Yang G, Smailus D, Jones S, Marra M, Schein J, Bakkeren G. Generation of a wheat leaf rust, Puccinia triticina, EST database from stage-specific cDNA libraries. Molecular Plant Pathology, 2007, 8(4): 451-467

84. Cantu D, Segovia V, MacLean D, Bayles R, Chen X, Kamoun S, Dubcovsky J, Saunders D G, Uauy C. Genome analyses of the wheat yellow (stripe) rust pathogen Puccinia striiformis f. sp. tritici reveal polymorphic and haustorial expressed secreted proteins as candidate effectors. BMC Genomics, 2013, 14(1): 270

85. Zheng W, Huang L, Huang J, Wang X, Chen X, Zhao J, Guo J, Zhuang H, Qiu C, Liu J, Liu H, Huang X, Pei G, Zhan G, Tang C, Cheng Y, Liu M, Zhang J, Zhao Z, Zhang S, Han Q, Han D, Zhang 
H, Zhao J, Gao X, Wang J, Ni P, Done W, Yang L, Yang H, Xu J, Zhang G, Kang Z. High genome heterozygosity and endemic genetic recombination in the wheat stripe rust fungus. Nature Communications, 2013, 4: 2673

86. Duplessis S, Cuomo C A, Lin Y C, Aerts A, Tisserant E, VeneaultFourrey C, Joly D L, Hacquard S, Amselem J, Cantarel B L, Chiu R, Coutinho P M, Feau N, Field M, Frey P, Gelhaye E, Goldberg J, Grabherr M G, Kodira C D, Kohler A, Kües U, Lindquist E A, Lucas S M, Mago R, Mauceli E, Morin E, Murat C, Pangilinan J L, Park R, Pearson M, Quesneville H, Rouhier N, Sakthikumar S, Salamov A A, Schmutz J, Selles B, Shapiro H, Tanguay P, Tuskan G A, Henrissat B, Van de Peer Y, Rouzé P, Ellis J G, Dodds P N, Schein J E, Zhong S, Hamelin R C, Grigoriev I V, Szabo L J, Martin F. Obligate biotrophy features unraveled by the genomic analysis of rust fungi. Proceedings of the National Academy of Sciences of the United States of America, 2011, 108(22): 91669171

87. Saunders D G, Win J, Cano L M, Szabo L J, Kamoun S, Raffaele S. Using hierarchical clustering of secreted protein families to classify and rank candidate effectors of rust fungi. PLoS ONE, 2012, 7(1): e29847

88. Dodds P N, Lawrence G J, Catanzariti A M, Ayliffe M A, Ellis J G. The Melampsora lini AvrL567 avirulence genes are expressed in haustoria and their products are recognized inside plant cells. The Plant Cell, 2004, 16(3): 755-768

89. Catanzariti A M, Dodds P N, Lawrence G J, Ayliffe M A, Ellis J G. Haustorially expressed secreted proteins from flax rust are highly enriched for avirulence elicitors. The Plant Cell, 2006, 18(1): $243-$ 256

90. Kemen E, Kemen A C, Rafiqi M, Hempel U, Mendgen K, Hahn M, Voegele R T. Identification of a protein from rust fungi transferred from haustoria into infected plant cells. Molecular Plant-Microbe Interactions, 2005, 18(11): 1130-1139

91. Upadhyaya N M, Mago R, Staskawicz B J, Ayliffe M A, Ellis J G, Dodds P N. A bacterial type III secretion assay for delivery of fungal effector proteins into wheat. Molecular Plant-Microbe Interactions, 2014, 27(3): 255-264
92. Rafiqi M, Gan P H, Ravensdale M, Lawrence G J, Ellis J G, Jones D A, Hardham A R, Dodds P N. Internalization of flax rust avirulence proteins into flax and tobacco cells can occur in the absence of the pathogen. The Plant Cell, 2010, 22(6): 2017-2032

93. Kemen E, Kemen A, Ehlers A, Voegele R, Mendgen K. A novel structural effector from rust fungi is capable of fibril formation. The Plant Journal, 2013, 75(5): 767-780

94. Dong Y L, Yin C T, Hulbert S, Chen X M, Kang Z S. Cloning and expression analysis of three secreted protein genes from wheat stripe rust fungus Puccinia striiformis f. sp. tritici. World Journal of Microbiology \& Biotechnology, 2011, 27(5): 1261-1265

95. Gu B, Kale S D, Wang Q, Wang D, Pan Q, Cao H, Meng Y, Kang Z, Tyler B M, Shan W. Rust secreted protein Ps87 is conserved in diverse fungal pathogens and contains a RXLR-like motif sufficient for translocation into plant cells. PLOS ONE, 2011, 6 (11): e27217

96. Guo J, Dai X, Xu J R, Wang Y, Bai P, Liu F, Duan Y, Zhang H, Huang L, Kang Z. Molecular characterization of a Fus3/Kss1 type MAPK from Puccinia striiformis f. sp. tritici, PsMAPK1. PLoS ONE, 2011, 6(7): e21895

97. Yin C, Jurgenson J E, Hulbert S H. Development of a host-induced RNAi system in the wheat stripe rust fungus Puccinia striiformis $\mathrm{f}$. sp. tritici. Molecular Plant-Microbe Interactions, 2011, 24(5): 554-561

98. Zhang H, Guo J, Voegele R T, Zhang J, Duan Y, Luo H, Kang Z. Functional characterization of calcineurin homologs PsCNA1/ PsCNB1 in Puccinia striiformis f. sp. tritici using a host-induced RNAi system. PLoS ONE, 2012, 7(11): e49262

99. Cheng Y, Wang X, Yao J, Voegele R T, Zhang Y, Wang W, Huang L, Kang Z. Characterization of protein kinase PSSRPKL, a novel pathogenicity factor in the wheat stripe rust fungus. Environmental Microbiology, 2015. DOI: 10.1111/1462-2920.12719 (first published online)

100. Tang C, Wei J, Han Q, Liu R, Duan X, Fu Y, Huang X, Wang X, Kang Z. PsANT, the adenine nucleotide translocase of Puccinia striiformis, promotes cell death and fungal growth. Scientific Reports, 2015, 5: 11241 